\title{
Cerebral near-infrared spectroscopy during cardiopulmonary bypass predicts superior vena cava oxygen saturation
}

\author{
Richard Ginther, CCP, ${ }^{\mathrm{a}}$ Vinod A. Sebastian, MD, ${ }^{\mathrm{b}}$ Rong Huang, MS, ${ }^{\mathrm{c}}$ Steven R. Leonard, MD, ${ }^{\mathrm{a}}$ \\ Ronald Gorney, PA-C, CCP, ${ }^{\mathrm{a}}$ Kristine J. Guleserian, MD, ${ }^{\mathrm{a}}$ and Joseph M. Forbess, MD ${ }^{\mathrm{a}}$
}

Objective: Cerebral and flank near-infrared spectroscopy are used to monitor tissue oxygenation during cardiopulmonary bypass in pediatric patients. We sought to validate these noninvasive measurements as predictors of oxygen saturation in the superior and inferior venae cavae during cardiopulmonary bypass.

\begin{abstract}
Methods: Eight patients underwent elective repair of congenital heart defects with bicaval cannulation. Ultrasonic flow probes and oximetric catheters were placed in the superior and inferior venae cavae limbs of the perfusion circuit. Cerebral and flank near-infrared spectroscopy and 12 additional variables were recorded each minute on cardiopulmonary bypass. Relationships between these variables and superior and inferior venae cavae oxygen saturation were analyzed by linear mixed modeling. The regression of superior vena cava oxygen saturation by current cerebral near-infrared spectroscopy and 1-minute lag cerebral near-infrared spectroscopy, which are equivalent to the regression of the superior vena cava saturation by the current cerebral nearinfrared spectroscopy and the 1-minute change in cerebral near-infrared spectroscopy, were used to assess cerebral near-infrared spectroscopy as a trend monitor.
\end{abstract}

Results: The mean number of observation time points per patient was 86 (median 72, range 34-194) for 690 total observations. The root mean square percentage error was $6.39 \%$ for the prediction model of superior vena cava saturation by single-factor cerebral near-infrared spectroscopy. The root mean square percentage error was $10.8 \%$ for the prediction model of inferior vena cava saturation by single-factor flank near-infrared spectroscopy.

Conclusions: Cerebral near-infrared spectroscopy accurately predicts superior vena cava oxygen saturation and changes in superior vena cava oxygen saturation on cardiopulmonary bypass. The relationship between flank near-infrared spectroscopy and inferior vena cava saturation is not as strong. (J Thorac Cardiovasc Surg 2011;142:359-65)

Near-infrared spectroscopy (NIRS) offers a noninvasive continuous estimate of the saturation of blood in the volume of tissue being monitored. This technology has been used to detect changes in organ perfusion in the perioperative period. Cerebral near-infrared spectroscopy (CNIRS) is now widely used in pediatric cardiac surgery. The application of a NIRS sensor to the flank (flank near-infrared spectroscopy [FNIRS]) and abdomen is also becoming more widely used. The major assumption underpinning the usefulness of

\footnotetext{
From the Division of Pediatric Cardiothoracic Surgery, ${ }^{\mathrm{a}}$ University of Texas Southwestern Medical Center and Children's Medical Center, Dallas, Tex; Division of Pediatric Cardiac Surgery, ${ }^{\mathrm{b}}$ Lucile Packard Children's Hospital, Stanford University, Palo Alto, Calif; and Research Department, ${ }^{\text {c }}$ Children's Medical Center Dallas, University of Texas Southwestern Medical Center at Dallas, Dallas, Tex.

Disclosures: Authors have nothing to disclose with regard to commercial support.

Poster presented at The 5th World Congress of Pediatric Cardiology and Cardiac Surgery, June 21-26, 2009, Cairns, Australia.

Received for publication Aug 24, 2010; revisions received Nov 4, 2010; accepted for publication Dec 16, 2010

Address for reprints: Vinod A. Sebastian, MD, Division of Pediatric Cardiac Surgery, Lucile Packard Children's Hospital, Stanford University, 725 Welch Rd, Palo Alto, CA 94304 (E-mail: v1977@stanford.edu).

0022-5223/\$36.00

Copyright (C) 2011 Published by Elsevier Inc. on behalf of The American Association for Thoracic Surgery

doi:10.1016/j.jtcvs.2010.12.021
}

NIRS is that these NIRS data correlate with mixed venous saturation of the monitored body region.

The aim of our study was to determine whether CNIRS and FNIRS data (Invos 5100; Somanetics, Troy, MI), measured during cardiopulmonary bypass (CPB), correlate with the oxygen saturation in the superior vena cava (SVC) and inferior vena cava (IVC) as measured by oximetric catheters placed in the SVC and IVC limbs of the CPB circuit. Our hypothesis was that CNIRS and FNIRS will strongly correlate with SVC and IVC saturation, respectively.

\section{PATIENTS AND METHODS}

\section{Study Population and Data Acquisition}

After institutional review board approval, we reviewed 8 patients undergoing elective repair of congenital heart defects with bicaval cannulation at Children's Medical Center Dallas between April and August 2008. CNIRS was obtained per routine in our program with the sensor placed over the right side of the forehead, and FNIRS was obtained with the sensor placed on the right flank, just caudal to the costal margin. The CPB circuit was modified as shown in Figure 1, and 5.5F oximetric catheters (Hospira model P575-10CM-EH) were placed into the SVC and IVC limbs of the CPB circuit. Doppler flow probes (Transonics, Inc, Ithaca, NY) were also placed on the SVC and IVC limbs of the circuit. For the purpose of this study, CNIRS, FNIRS, and 12 additional variables were recorded each minute on CPB. Routine caval snaring on CPB eliminated the 


\section{Abbreviations and Acronyms \\ CNIRS $=$ cerebral near-infrared spectroscopy \\ $\mathrm{CPB}=$ cardiopulmonary bypass \\ FNIRS = flank near-infrared spectroscopy \\ IVC = inferior vena cava \\ NIRS = near-infrared spectroscopy \\ $\mathrm{SVC}=$ superior vena cava}

possibility of caval contamination from intracardiac shunting. In this study, all patients were managed with alpha-stat strategy during CPB. The mean nadir rectal temperature was $30.3^{\circ} \mathrm{C}$. All other clinical intraoperative management of the patients was routine.

\section{Statistical Analysis}

The linear mixed regression model for repeated measures was used to account for the hierarchic structure of the data. The multivariate model was used to investigate the relationship between SVC/IVC saturations and a number of predictor variables simultaneously. The multivariate prediction models were based on the training data, which were randomly chosen from the complete data and were $75 \%$ of the total observations. The forward stepwise selection of predictors was used to build the models. The multivariate models were then cross-validated by another $25 \%$ of the total observations. Time series analysis was used to validate that CNIRS can be a trend monitor for SVC saturation. SVC saturations were modeled by current CNIRS and 1-minute lag CNIRS value. The model was fitted to the initial $90 \%$ of the data per patient, and the last $10 \%$ data were used as validation. The overall root mean square percentage error for each patient was used as the validation criteria for both models. The lower the root mean squared percentage error, the more accurate the prediction method. All data were analyzed with SAS V.9.2 (SAS Institute, Inc, Cary, NC).

\section{RESULTS}

Patient characteristics and operative data are shown in Table 1 . The mean number of observation time points per

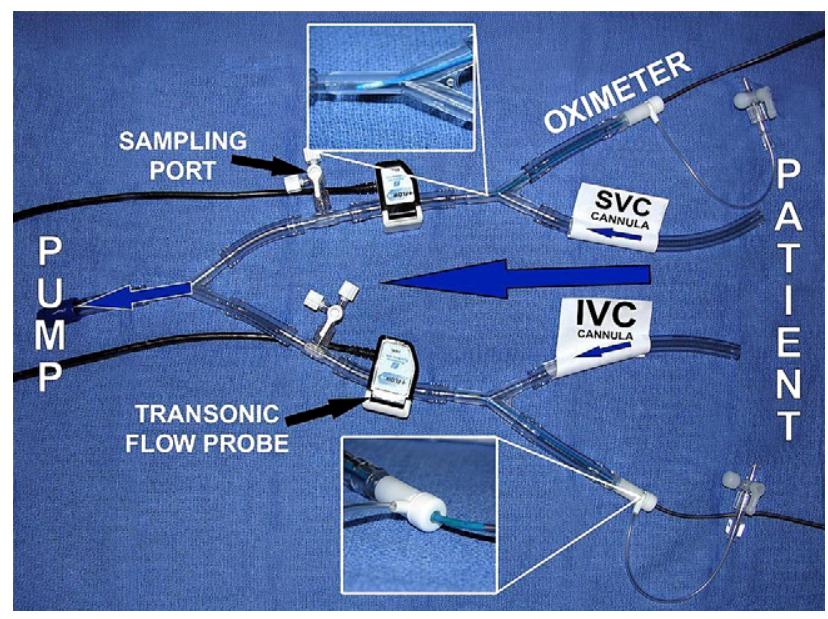

FIGURE 1. Modification of $\mathrm{CPB}$ circuit that allows for oximetric catheter measurement of SVC and IVC saturation. Blood flow in SVC and IVC limbs of the circuit was measured with Doppler flow probes placed on the limbs of the venous return circuit. Sampling ports were placed in the IVC and SVC limbs of the circuit to allow for appropriate calibration of the oximetric catheters. $I V C$, Inferior vena cava; $S V C$, superior vena cava.
TABLE 1. Patient characteristics and operative data

\begin{tabular}{lccc}
\hline & Mean & SD & Range \\
\hline Weight $(\mathrm{kg})$ & 34.0 & 28.8 & $12.4-62$ \\
Age $(\mathrm{y})$ & 8.1 & 6.1 & $2-15$ \\
CPB time (min) & 75.9 & 19.3 & $54-113$ \\
Aortic crossclamp time (min) & 47.0 & 18.1 & $16-78$ \\
SVC $(\%)$ & 88.4 & 7.6 & $64-100$ \\
IVC $(\%)$ & 84.3 & 10.5 & $28-100$ \\
CNIRS $(\%)$ & 81.2 & 11.3 & $45-95$ \\
FNIRS $(\%)$ & 85.4 & 9.6 & $49-95$ \\
SVC flow $(\mathrm{L} / \mathrm{min})$ & 0.70 & 0.25 & $-0.02-1.32$ \\
IVC flow $(\mathrm{L} / \mathrm{min})$ & 0.92 & 0.45 & $-0.01-3.20$ \\
Pump flow $(\mathrm{L} / \mathrm{min})$ & 1.8 & 0.7 & $-0.01-3.60$ \\
Mean arterial pressure $(\mathrm{mm} \mathrm{Hg})$ & 39.3 & 11.2 & $12-94$ \\
Hemoglobin $(\mathrm{g} / \mathrm{dL})$ & 11.6 & 1.5 & $8.8-23.5$ \\
Hematocrit $(\%)$ & 34.3 & 4.5 & $26-70$ \\
Nasoesophageal temperature $\left({ }^{\circ} \mathrm{C}\right)$ & 31.4 & 3 & $24.2-37.4$ \\
Rectal temperature $\left({ }^{\circ} \mathrm{C}\right)$ & 32.2 & 2.3 & $27.8-36.9$ \\
Venous temperature $\left({ }^{\circ} \mathrm{C}\right)$ & 31.1 & 3.1 & $22.7-37.6$ \\
Oxygenator temperature $\left({ }^{\circ} \mathrm{C}\right)$ & 31.4 & 3.9 & $24.9-38.7$ \\
\hline
\end{tabular}

$S D$, Standard deviation; $S V C$, superior vena cava; IVC, inferior vena cava; CNIRS, cerebral near-infrared spectroscopy; FNIRS, flank near-infrared spectroscopy.

patient was 85 (median, 72; range, 34-194), accounting for a total of 690 observations. The cardiac diagnoses and procedure performed are listed in Table 2 . The scatter plot in Figure 2 shows the linear association between CNIRS and SVC saturation. The Pearson correlation coefficient was $0.77(P<.001)$ between CNIRS and SVC saturation,

TABLE 2. Patient diagnoses and operative procedure

\begin{tabular}{|c|c|c|}
\hline Patient No. & Cardiac diagnoses & Procedure performed \\
\hline 1 & PS & $\begin{array}{l}\text { Pulmonary valvuloplasty, } \\
\text { subvalvar resection }\end{array}$ \\
\hline 2 & $\begin{array}{l}\text { AS, s/p interrupted } \\
\text { aortic arch repair }\end{array}$ & $\begin{array}{l}\text { Valve sparing, modified } \\
\text { Konno procedure }\end{array}$ \\
\hline 3 & $\begin{array}{l}\text { Single ventricle, } \\
\text { unbalanced } \\
\text { atrioventricular septal } \\
\text { defect, double-outlet } \\
\text { right ventricle, PS, s/p } \\
\text { bidirectional Glenn, } \\
\text { atrial septectomy, PA } \\
\text { banding }\end{array}$ & $\begin{array}{l}\text { Fenestrated modified } \\
\text { Fontan procedure, left } \\
\text { SVC ligation }\end{array}$ \\
\hline 4 & $\begin{array}{l}\text { Perimembranous VSD, } \\
\text { RVOT obstruction }\end{array}$ & $\begin{array}{l}\text { VSD patch repair, RVOT } \\
\text { resection }\end{array}$ \\
\hline 5 & Secundum ASD & ASD repair with patch \\
\hline 6 & Mitral regurgitation & Mitral valvuloplasty \\
\hline 7 & $\begin{array}{l}\text { RV-PA conduit } \\
\text { insufficiency and } \\
\text { stenosis }\end{array}$ & RV-PA conduit replacement \\
\hline 8 & Subvalvar AS & $\begin{array}{l}\text { Sub-AS resection, } \\
\text { myectomy }\end{array}$ \\
\hline
\end{tabular}

$\overline{A S \text {, Aortic stenosis; } P S \text {, pulmonary stenosis; } A S D \text {, atrial septal defect; } R V O T \text {, right }}$ ventricular outflow tract; $V S D$, ventricular septal defect; $R V-P A$, right ventricle to pulmonary artery; $S V C$, superior vena cava; $P A$, pulmonary artery. 

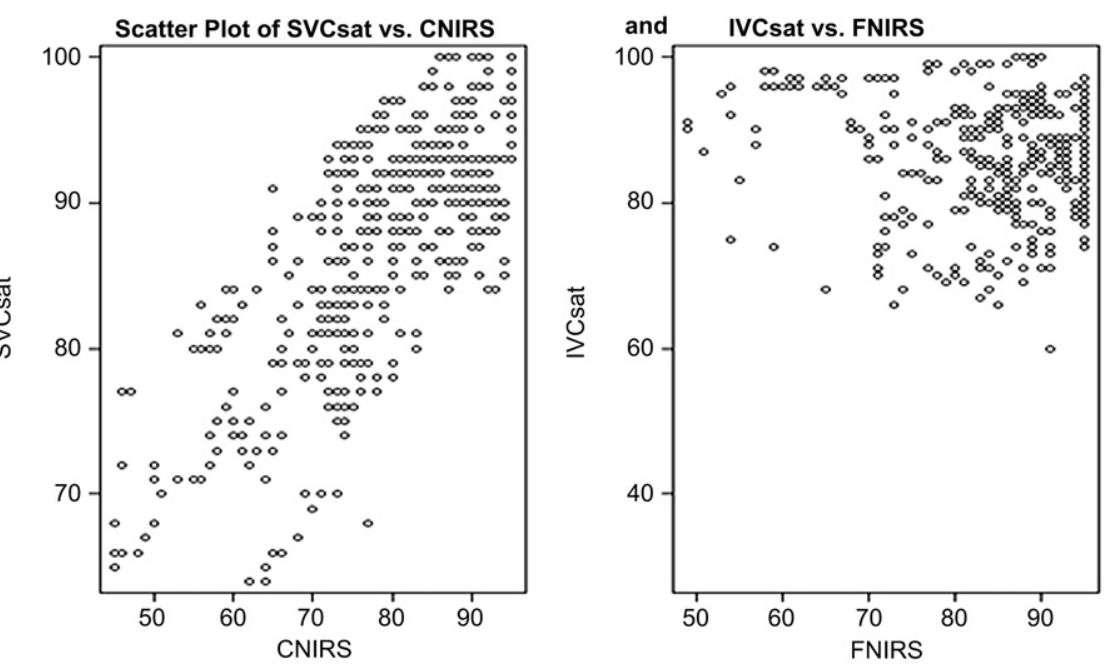

A

Pearson Correlation with SVC and IVC

\begin{tabular}{|c|c|c|c|c|}
\hline & correlation coefficent with SVC & $p$ value & $\begin{array}{l}\text { correlation coefficent } \\
\text { with IVC }\end{array}$ & p value \\
\hline CNIRS (\%) & 0.77 & $\cdots$ & 0.07 & \\
\hline FNIRS (\%) & -0.14 & $\bullet$ & -0.104 & - \\
\hline SVC Flow (liter/min) & 0.30 & $\cdots$ & -0.014 & \\
\hline IVC Flow (liter/min) & -0.008 & & 0.059 & \\
\hline Pump Flow (liter/min) & 0.02 & & -0.21 & $\cdots$ \\
\hline Mean Arterial Pressure (mmHg) & 0.20 & $\cdots$ & -0.077 & \\
\hline Hemoglobin (gm/dl) & 0.37 & ... & -0.027 & \\
\hline Hematocrit (\%) & 0.40 & $\cdots$ & 0.008 & \\
\hline Nasoesophogeal Temperature $\left({ }^{\circ} \mathrm{C}\right)$ & -0.57 & $\cdots$ & -0.38 & $\cdots$ \\
\hline Rectal Temperature $\left({ }^{\circ} \mathrm{C}\right)$ & -0.19 & .. & -0.34 & $\bullet$ \\
\hline Venous Temperature $\left({ }^{\circ} \mathrm{C}\right)$ & -0.61 & $\cdots$ & -0.61 & $\cdots$ \\
\hline Oxygenator Temperature $\left({ }^{\circ} \mathrm{C}\right)$ & -0.56 & .. & -0.56 & $\cdots$ \\
\hline
\end{tabular}

FIGURE 2. A, Scatter plot of SVC saturation/CNIRS and IVC saturation/FNIRS. B, Pearson correlation coefficient between 12 factors and SVC/IVC saturation. $* * * P<.001 ; * * P<.01 ; * P<.05$. The above data is from the 8 study patients. The Pearson correlation coefficient between SVC saturation and CNIRS is $0.77(P<.001)$ and is $-0.10(P<.05)$ between FNIRS and IVC saturation. SVCsat, Superior vena cava saturation; IVCsat, inferior vena cava saturation; CNIRS, cerebral near-infrared spectroscopy; FNIRS, flank near-infrared spectroscopy.

and $-0.10(P<.05)$ between FNIRS and IVC saturation (Figure 2). The large correlation coefficient and its statistical significance suggest a strong association between CNIRS and SVC saturation. The negative sign and the small value of the correlation coefficient between FNIRS and IVC saturation suggest that FNIRS is not a good predictor for IVC saturation. Temperatures measured at various locations were all negatively correlated with SVC saturation and IVC saturation. SVC flow, mean arterial pressure, hemoglobin, and hematocrit, which are all related to the transportation of oxygen, were positively correlated with SVC saturation.

The root mean square percentage error for the prediction model of SVC saturation by single-factor CNIRS was $6.39 \%$. The correlation coefficient between the predicted SVC saturation and the true SVC saturation was $76 \%$. The root mean square percentage error decreased to $4.69 \%$ when 5 other factors (in order, rectal temperature, IVC flow, oxygenator temperature, SVC flow, and arterial blood $\mathrm{pH}$ value) were added in the predictive model. The correlation coefficient between the predicted SVC saturation (from the 6-variable model) and true SVC saturation was $88 \%$. Among the studied variables, FNIRS was the strongest single predictor of IVC saturation $(P<.001)$. The root mean square percentage error was $10.8 \%$ for the prediction model of IVC saturation by single-factor FNIRS. The root mean square percentage error decreased to $8.29 \%$ when 2 other factors (nasal temperature and IVC flow) were added in the predictive model (Figure 3). The correlation coefficient between the predicted IVC saturation (from the 3-variable model) and true IVC saturation was only $53 \%$. Figures 4 and 5 show the CNIRS and SVC saturation time series for all 8 patients. The CNIRS trends correlate with SVC saturation trends in these patients. The root mean square percentage error varied across patients (from $2.96 \%$ to $16.8 \%$ ). The 


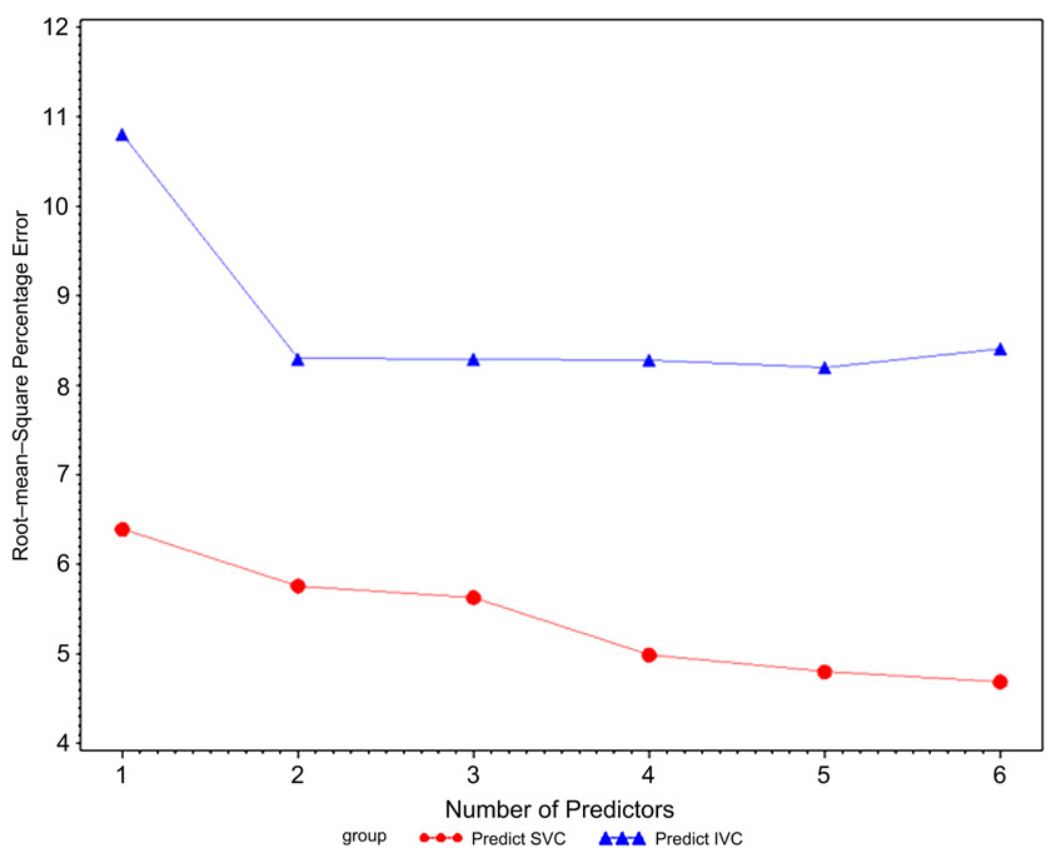

FIGURE 3. The root mean square percentage error for the prediction model of SVC saturation by single-factor CNIRS was $6.39 \%$. The root mean square percentage error decreased to $4.69 \%$ when 5 other factors (in order, rectal temperature, IVC flow, oxygen temperature, SVC flow, and arterial blood pH value) were added in the predictive model. The root mean square percentage error for the prediction model of IVC saturation by single-factor FNIRS was $10.8 \%$. The root mean square percentage error decreased to $8.29 \%$ when 2 other factors (nasal temperature and IVC flow) were added in the predictive model. $S V C$, Superior vena cava; $I V C$, inferior vena cava.

median and mean root mean square percentage errors for all 8 patients were $5.0 \%$ and $6.9 \%$, respectively. This was likely due to measurement error when using CNIRS, which was most commonly caused by the CNIRS probe becoming dislodged from the patient's forehead and thus leading to false values. When CNIRS is measured correctly, CNIRS trends represent SVC trends accurately.

\section{DISCUSSION}

NIRS monitors a weighted average of blood in small gasexchanging vessels: arterioles, capillaries, and venules. The thin extracerebral tissues in children decrease the interference with brain monitoring in CNIRS. NIRS relies on the relative transparency of biological tissues to near-infrared light $(700-900 \mathrm{~nm})$ to determine tissue oxygenation. Oxyhemoglobin and dexoxyhemoglobin and cytochrome aa3 possess distinct absorption characteristics in the near-infrared spectrum, and this concept is used in NIRS monitoring. By monitoring absorption at wavelengths where oxyhemoglobin, deoxyhemoglobin, and cytochrome aa3 differ, it is possible to determine the concentrations of oxyhemoglobin, deoxyhemoglobin, and cytochrome aa3, and thus calculate hemoglobin oxygen saturation. NIRS differs from pulse oximetry in that the latter uses the pulsatile component of the tissue absorption signal and the former uses the 100-fold stronger nonpulsatile component of the tissue absorption signal. Thus, NIRS is far less susceptible to failure from poor perfusion than pulse oximetry.

Both pulse oximetry and NIRS are accepted methods for noninvasive monitoring of arterial and regional tissue oxygenation. ${ }^{1}$ However, optimization of systemic oxygen delivery as a perioperative management strategy, with mixed venous saturation as a primary target, has been shown to be associated with lower early mortality ${ }^{2-4}$ and improved outcomes. $^{5,6}$ In neonates with hypoplastic left heart syndrome, the use of arterial saturation as an index of pulmonary/systemic balance is confounded by the potential for pulmonary venous desaturation at low inspired oxygen fraction and progressive systemic venous desaturation as the pulmonary to systemic blood flow ratio increases. ${ }^{7,8}$

Nagdyman and colleagues ${ }^{9}$ conducted a prospective observational study of 31 children in a catheterization laboratory and noted strong correlation between regional cerebral oxygenation index measured by INVOS 5100 and venous oxygen saturation in the jugular bulb. NIRS monitoring of tissue oxygen delivery can help in the management of critically ill patients during $\mathrm{CPB}$. A recent study of neonates after the Norwood procedure showed that prolonged exposure to low cerebral oxygen saturation $(<45 \%$ for $>180 \mathrm{~min}-$ utes) was associated with the development of ischemic lesions on magnetic resonance imaging. ${ }^{10}$ NIRS has been shown to be useful as a real-time monitoring of patients 

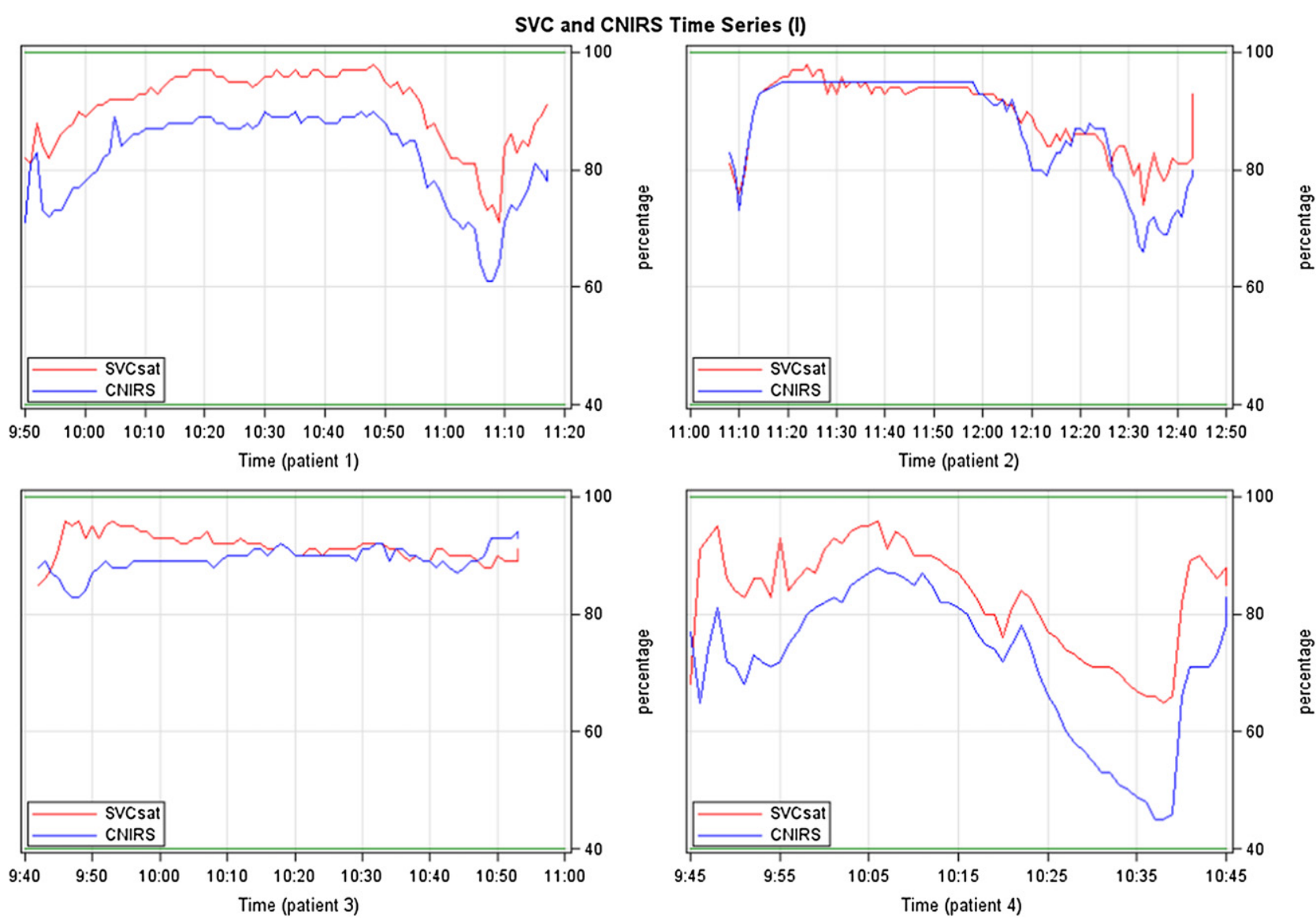

FIGURE 4. CNIRS and SVC saturation time series for all 8 patients. SVC, Superior vena cava; CNIRS, cerebral near-infrared spectroscopy; SVCsat, superior vena cava saturation.

before and after stage I palliation for hypoplastic left heart syndrome. ${ }^{11,12}$ Cerebral oxygen saturation measured by NIRS in neonates after the Norwood procedure has been shown to correlate positively to systemic arterial pressure, arterial oxygen saturation, and arterial oxygen tension, and negatively to oxygen extraction ratio. ${ }^{11}$ Kirshbom and colleagues $^{13}$ evaluated the use of NIRS in awake patients with single ventricles in the outpatient setting. Vital signs (heart rate, blood pressure, respiratory rate), pulse oximetry, and NIRS were measured in 20 patients with single ventricles before routine cardiac catheterization to evaluate the best noninvasive predictor of SVC saturation as a marker for the adequacy of systemic oxygen delivery. By using stepwise multiple regression analysis, they generated a model in which only NIRS was a significant independent predictor of SVC saturation.

Baraka and colleagues ${ }^{14}$ reviewed 14 adult patients undergoing coronary artery bypass graft surgery and noted an increase in mixed venous oxygen saturation associated with a paradoxical decrease in cerebral oxygen saturation during moderately hypothermic $\left(28^{\circ} \mathrm{C}-30^{\circ} \mathrm{C}\right) \mathrm{CPB}$. They attributed this to the low temperature-corrected arterial carbon dioxide tension values. During tepid CPB $\left(33^{\circ} \mathrm{C}-34^{\circ} \mathrm{C}\right)$ after rewarming, they noted an increase in regional cerebral oxygen saturation and better correlation between cerebral oxygen saturation and mixed venous oxygen saturation. The mean age of the patients in our series was 8.1 years, and the mean nadir rectal temperature was $30.3^{\circ} \mathrm{C}$, which would make our study group different from Baraka and colleagues' study group. However, in our predictive model, we did note a negative correlation between temperature and SVC/IVC saturation. Further studies will be needed to examine the effect of extreme changes in temperature on the relationship between CNIRS and SVC saturation in the pediatric population.

The potential usefulness of NIRS monitoring is based on the assumption that NIRS data correlate with mixed venous saturation of the tissue bed being monitored. This study sought to validate these noninvasive NIRS measurements as predictors of oxygen saturation in the superior and inferior venae cavae during CPB. CNIRS accurately predicted SVC saturation and changes in SVC saturation during 

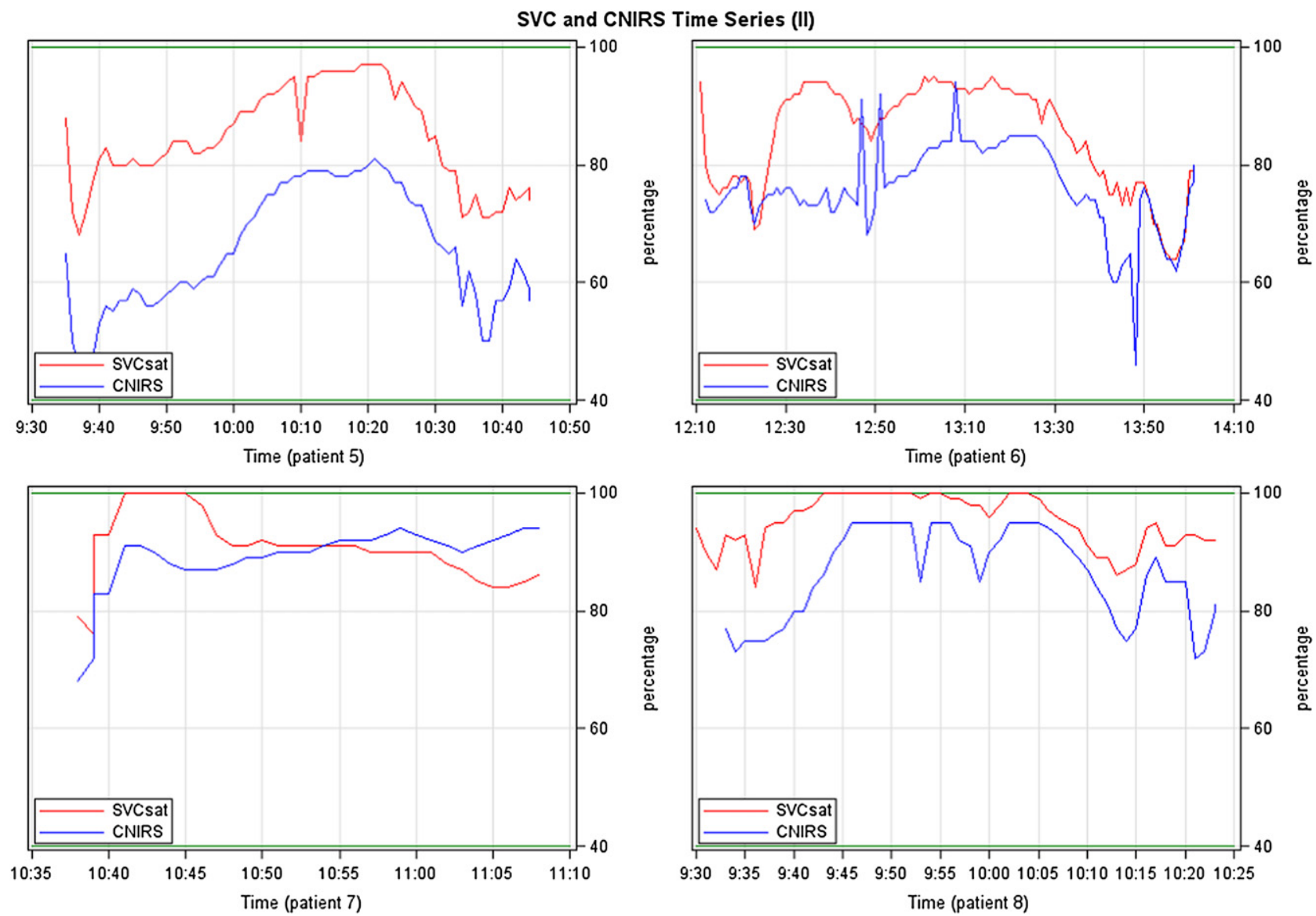

FIGURE 5. CNIRS and SVC saturation time series for all 8 patients. SVC, Superior vena cava; CNIRS, cerebral near-infrared spectroscopy; SVCsat, superior vena cava saturation.

CPB. The relationship between FNIRS and IVC saturation was not as strong.

\section{CONCLUSIONS}

CNIRS is an accurate noninvasive predictor of SVC saturation on CPB and strongly predicts changes or trends in SVC saturation on CPB. FNIRS, although significantly associated with IVC saturation, is not as strong a predictor of IVC saturation. Further investigation is warranted to determine the accuracy and predictive value of FNIRS. Additional studies are also necessary to determine the value of CNIRS at lower temperatures on CPB.

The authors thank David Leonard, $\mathrm{PhD}$, for additional assistance with statistical analyses.

\section{References}

1. Tortoriello TA, Stayer SA, Mott AR, McKenzie ED, Fraser CD, Andropoulos DB, et al. A noninvasive estimation of mixed venous oxygen saturation using near-infrared spectroscopy by cerebral oximetry in pediatric cardiac surgery patients. Paediatr Anaesth. 2005;15:495-503.
2. Tweddell JS, Hoffman GM, Fedderly RT, Berger S, Thomas JP Jr, Ghanayem NS, et al. Phenoxybenzamine improves systemic oxygen delivery after the Norwood procedure. Ann Thorac Surg. 1999;67:161-7.

3. Tweddell JS, Hoffman GM. Postoperative management in patient with complex congenital heart disease. Semin Thorac Cardiovasc Surg Pediatric Card Surg Annu. 2002;5:187-205.

4. Wright GE, Crowley DC, Charpie JR, Ohye RG, Bove EL, Kulik TJ. High systemic vascular resistance and sudden cardiovascular collapse in recovering Norwood patients. Ann Thorac Surg. 2004;77:48-52.

5. Tweddell JS, Ghanayem NS, Mussatto KA, Mitchell ME, Lamers LJ, Musa NL, et al. Mixed venous oxygen saturation monitoring after stage I palliation for hypoplastic left heart syndrome. Ann Thorac Surg. 2007;84: 1301-11.

6. Tweddell JS, Hoffman GM, Mussatto KA, Fedderly RT, Berger S, Jaquiss RD, et al. Improved survival of patients undergoing palliation of hypoplastic left heart syndrome: lessons learned from 115 consecutive patients. Circulation. 2002;106(12 Suppl. 1):I82-9.

7. Taeed R, Schwartz SM, Pearl JM, Raake JL, Beekman RH 3rd, Manning PB, et al. Unrecognized pulmonary venous desaturation early after Norwood palliation confounds Qp:Qs assessment and compromises oxygen delivery. Circulation. 2001;103:2699-704.

8. Hoffman GM, Tweddell JS, Ghanayem NS, Mussatto KA, Stuth EA, Jacquis RD, et al. Alteration of the critical arteriovenous oxygen saturation relationship by sustained afterload reduction after the Norwood procedure. J Thorac Cardiovasc Surg. 2004;127:738-45.

9. Nagdyman N, Ewert P, Peters B, Miera O, Fleck T, Berger F. Comparison of different near-infrared spectroscopic cerebral oxygenation indices with central 
venous and jugular venous oxygenation saturation in children. Paediatr Anaesth. 2008;18:160-6.

10. Dent CL, Spaeth JP, Jones BV, Schwartz SM, Glauser TA, Hallinan B, et al. Brain magnetic resonance imaging abnormalities after the Norwood procedure using regional cerebral perfusion. J Thorac Cardiovasc Surg. 2005;130:1523-30.

11. Li J, Zhang G, Holtby H, Guerguerian AM, Cai S, Humpl T, et al. The influence of systemic hemodynamics and oxygen transport on cerebral oxygen saturation in neonates after the Norwood procedure. J Thorac Cardiovasc Surg. 2008; 135:83-90.
12. Johnson BA, Hoffman GM, Tweddell JS, Cava RS, Basir M, Mitchell ME, et al Near-infrared spectroscopy in neonates before palliation of hypoplastic left heart syndrome. Ann Thorac Surg. 2009;87:571-9.

13. Kirshbom PM, Forbess JM, Kogon BE, Simsic JM, Kim DW, Raviele AA, et al. Cerebral near infrared spectroscopy is a reliable marker of systemic perfusion in awake single ventricle children. Pediatr Cardiol. 2007;28:42-5.

14. Baraka A, Naufal M, El-Khatib M. Correlation between cerebral and mixed venous oxygen saturation during moderate versus tepid hypothermic hemodiluted cardiopulmonary bypass. J Cardiothoracic Vasc Anesth. 2006;20:819-25. 